\title{
Motricidade humana como tema de produção em periódicos da educação física brasileira
}

\author{
Human motricity as production theme in brazilian physical education journals \\ Motricidad humana como tema de producción en periódicos de la educación física brasileña \\ CAe Rodrigues ${ }^{1}$; Fabio Zoboli ${ }^{2}$; Luis HenRiQue Calazans ${ }^{3}$ \\ Universidade FEderal de SergiPe, UFS, São Cristóvão-SE, BraSIL
}

\begin{abstract}
RESUMO
$\mathrm{O}$ artigo analisa a produção do conhecimento da temática Motricidade Humana (MH) em 12 periódicos da Educação Física brasileira classificados como A e B pelo WebQualis da Capes no período de 2000-2015. Metodologicamente se caracterizou como um estudo quali-quantitativo de caráter bibliométrico. Como resultado foram encontrados 10 artigos e a análise do corpus indica que (a) a teoria da MH está fortemente vinculada aos cursos de formação em Educação Física do estado de São Paulo e (b) a veiculação de publicações sobre o tema se dá, predominantemente, em periódicos Paulistas. As temáticas abordadas nos artigos foram: (a) textos epistemológicos de análise da produção de conhecimento; (b) textos epistemológicos que tratam da concepção de corpo e saúde; (c) estudos que apresentam possibilidades com os tratos metodológicos no ensino das práticas corporais relacionadas à aplicação em escolas e na formação inicial universitária; (d) textos que versam sobre práticas corporais sob o viés da $\mathrm{MH}$.
\end{abstract}

Palavras-chave: Produção do Conhecimento. Educação Física. Brasil. Bibliometria. Motricidade Humana.

\begin{abstract}
The article analyzes the production of knowledge about Human Motricity (HM) in 12 Brazilian Physical Education journals classified as A and B by Capes-WebQualis during the period of 2000-2015. Methodologically, the study is characterized as a quali-quantitative bibliometric study. As a result, 10 articles met the established criteria; the analysis of this corpus indicates that (a) the theory of HM is strongly linked to Physical Education programs in higher education settings in the state of São Paulo and (b) the publication of the subject occurs, predominantly, in journals also published in São Paulo state. The themes addressed in the articles were: (a) epistemological texts of knowledge production analysis; (b) epistemological texts dealing with the conception of body and health; (c) studies that present possibilities in methodologies in the teaching of corporal practices related to elementary school and higher education settings; (d) texts that deal with corporeal practices under the bias of HM.
\end{abstract}

Keywords: Knowledge Production. Physical Education. Brazil. Bibliometric Research. Human Motricity.

\section{RESUMEN}

El artículo analiza la producción del conocimiento de la temática Motricidad Humana (MH) en 12 periódicos de la Educación Física brasileña clasificados como A y B por la WebQualis de la Capes en el período 2000-2015. Metodológicamente se caracterizó como un estudio cualitativo cuantitativo de carácter bibliométrico. Como resultado se encontraron 10 artículos y el análisis del corpus indica que (a) la teoría de la MH está fuertemente vinculada a los cursos de formación en Educación Física del estado de São Paulo y (b) la publicación de publicaciones sobre el tema se da, predominantemente, en periódicos Paulistas. Las temáticas abordadas en los artículos fueron: (a) textos epistemológicos de análisis de la producción de conocimiento; (b) textos epistemológicos que tratan de la concepción de cuerpo y salud; (c) estudios que presentan posibilidades con los tratos metodológicos en la enseñanza de las prácticas corporales relacionadas a la aplicación en escuelas y en la formación inicial universitaria; (d) textos que versan sobre prácticas corporales bajo el sesgo de la MH.

Palabras clave: Producción del Conocimiento. Educación Física. Brasil. Bibliometría. Motricidad Humana.

\footnotetext{
${ }^{1}$ Professor do Departamento de Educação Física e do Programa de Pós-Graduação em Desenvolvimento e Meio Ambiente da UFS. E-mail: rodrigues.cae@gmail.com

${ }^{2}$ Professor do Departamento de Educação Física e do Programa de Pós-Graduação em Educação da UFS. Email: zobolito@gmail.com

${ }^{3}$ Graduando do Curso de Licenciatura em Educação Física da UFS. E-mail: luishcalazans@gmail.com
} 


\section{INTRODUÇÃO}

Os últimos anos do século passado e os primeiros anos deste novo milênio foram permeados por vários questionamentos no contexto da Educação Física brasileira no que tange as questões de cunho epistemológico. A partir da crise que fez da década de 1980 um marco histórico para a Educação Física no Brasil, muitas propostas teóricas apontavam na direção de uma Educação Física mais preocupada com dimensões sociais e políticas a fim de combater um reducionismo técnico/biologicista dominante até então.

Dentro desse contexto surgem várias correntes teóricas, dentre as quais a teoria da Ciência da Motricidade Humana $(\mathrm{CMH})$ cunhada pelo português Manuel Sérgio Vieira e Cunha. Manuel Sérgio apresentou sua tese sobre a Ciência da Motricidade Humana em julho de 1986, no Instituto Superior de Educação Física da Universidade Técnica de Lisboa-Portugal.

Manuel Sérgio esteve em Campinas-SP onde atuou como professor visitante na Universidade de Campinas (UNICAMP), nos anos de 1987 e 1988, quando participou das discussões que buscavam uma matriz teórica para a Educação Física brasileira. Foi na UNICAMP que Manuel Sérgio tentou ativamente a implantação da Ciência da Motricidade Humana como matriz teórica, depois do aprofundamento das discussões com outros profissionais de Educação Física que lecionavam naquela instituição, dentre os quais podemos destacar: João Batista Andreotti Gomes Tojal, João Batista Freire, Ídico Luiz Pellegrinotti, Wagner Wey Moreira e Ademir Gebara.

A preocupação da obra de Manuel Sérgio sempre foi fundamentalmente ampliar os limites e a compreensão da Educação Física para além da prática em si e por consequência, para além dos reducionismos no que tange a visão de ser humano/corpo sob a qual a mesma está pautada. A teoria da Motricidade Humana critica severamente a visão de corpo e de movimento sob a qual a prática mecanicista da Educação Física é orientada.

Os estudos de Manuel Sérgio são caracterizados pela influência da filosofia e das demais ciências humanas. Sérgio parece não compreender o desenvolvimento de uma Educação Física que não fosse fundada em uma matriz filosófica clara. Para ele, mesmo as questões didático/pedagógicas tinham uma denotada raiz filosófica. Na década de 1970, Manuel Sérgio já se preocupava com a busca de uma Matriz Epistemológica para a Educação Física, dando início a uma forte e longínqua relação entre esta e a filosofia. Tal relação foi se acentuando das mais diversas formas, indo desde discussões sobre a necessidade de inclusão de uma disciplina específica de "Filosofia das Atividades Corporais" para o assunto nos cursos de graduação, até a abertura de espaços epistemológicos visando à sistematização da Ciência da Motricidade Humana.

A atenção para as questões epistemológicas e ontológicas para este intelectual português está diretamente ligada ao seu conceito de Motricidade Humana, que vai muito além da Educação Física, incluindo: a ergonomia, a reabilitação, o desporto, a dança e o circo.

Costuma-se posicionar a década de 1980 e o seu "movimento renovador" (CAPARROZ; BRACHT, 2007) às possibilidades de se pensar a Educação Física como disciplina acadêmica que produz seus próprios conhecimentos, relativizando assim, seu colonialismo epistemológico (GAMBOA, 1995) em relação às ciências-mãe, como a Biologia, a Biomecânica, a Psicologia, a Sociologia etc.

A prática de mapear e avaliar a produção de conhecimento na área da Educação Física, desde então, está aos poucos se tornando recorrente e relevante, ao mesmo tempo em que se configura mais claramente como um campo acadêmico. Portanto, a proposição deste artigo é verificar em periódicos com o conceito A1, A2, B1, B2, B3 e 
B4, classificados no Webqualis, a produção da área com o tema da "Motricidade Humana". Esta prática de mapear a produção do conhecimento de uma determinada área é uma característica de campos acadêmicos consolidados ou que estão em consolidação; sendo assim, se apresenta como uma necessidade para pensar ou nortear a constituição do seu próprio desenvolvimento.

Em se tratando do campo acadêmico da Educação Física, esse tipo de investigação é recente. De certa forma, esse atraso pode ser explicado pelo fato de a disciplina, durante muito tempo, ter sido considerada, conforme nos apontou Bracht (1999), muito mais uma área de aplicação do que de produção de conhecimento.

Segundo Bracht et al. $(2011 ; 2012)$, trabalhos similares no campo analisam a produção do conhecimento na área da Educação Física. O objetivo que é perseguido nesses estudos é, normalmente, identificar possíveis tendências das investigações em termos de temáticas e de contribuições teórico-metodológicas que foram utilizadas. Para Romanowski e Ens (2006, p. 39), as pesquisas do tipo "estado da arte":

\begin{abstract}
[...] podem significar uma contribuição importante na constituição do campo teórico de uma área de conhecimento, pois procuram identificar os aportes significativos da construção da teoria e prática pedagógica, apontar as restrições sobre o campo em que se move a pesquisa, as suas lacunas de disseminação, identificar experiências inovadoras investigadas que apontem alternativas de solução para os problemas da prática e reconhecer as contribuições da pesquisa na constituição de propostas na área focalizada.
\end{abstract}

A fim de compreender como o tema "Motricidade Humana" vem sendo discutido em periódicos da Educação Física estruturamos o presente artigo em 3 partes: num primeiro momento contextualizamos e apresentamos brevemente a Ciência da Motricidade Humana enquanto concepção epistemológica; na sequência dissertamos sobre nossa opção metodológica; para num terceiro e último momento apresentarmos e analisarmos os dados de nosso estudo.

\title{
CIÊNCIA DA MOTRICIDADE HUMANA: BREVE APRESENTAÇÃO E CONTEXTUALIZAÇÃo
}

Pensar em Educação Física nos anos de 1980 é trazer à tona a tão ainda hoje lembrada crise da Educação Física. Nessa época, as relações entre Educação Física e sociedade passaram a ser discutidas sob a influência das teorias críticas da educação: questionava-se seu papel e sua dimensão política. Ocorria nesse momento uma mudança de enfoque, tanto no que diz respeito à natureza da área quanto no que se refere aos objetivos, conteúdos e pressupostos pedagógicos de ensino e aprendizagem. No primeiro, enfatizavam-se as dimensões psicológicas, sociais, cognitivas e afetivas, concebendo o aluno como ser humano integral. No segundo, abarcavam-se objetivos educacionais mais amplos (não apenas voltados para a formação de um físico que possa sustentar a atividade intelectual), conteúdos diversificados (não só exercícios e esportes) e pressupostos pedagógicos mais humanos (e não apenas o adestramento técnico).

Sendo assim, as preocupações pedagógicas e filosóficas "entram em campo": nascia uma Educação Física mais crítica em termos políticos. O livro de João Paulo Subira Medina, "A Educação Física cuida do corpo e mente" lançado no ano de 1983 (MEDINA, 1983), a obra "Metodologia do ensino de Educação Física", conhecida também como "Coletivo de Autores", publicada em 1992 (Carmen Lúcia Soares, Celi Nelza Zülke Taffarel, Elizabeth Varjal, Lino Castellani Filho, Micheli Ortega Escobar e Valter Bracht) (Soares et al., 1992) e o livro "Educação Física: ensino e mudanças", lançado em 1991 por Elenor Kunz (KUNZ, 1991), apresentavam uma Educação Física crítica e reflexiva, superadora e emancipatória. Esses e outros livros são ainda hoje 
ícones dessa época de crise, que culminou na inserção das ciências sociais e humanas na Educação Física.

Imbricado a isto este período foi permeado por vários questionamentos no contexto da Educação Física brasileira no que tange as questões de cunho epistemológico. Como falar de Educação Física frente aos ecos de sua crise epistemológica e científica? Qual o objeto de estudo da Educação Física? A Educação Física está a reboque de outras ciências? Como situar problemas e contendas presentes na Educação Física que são originalmente problematizações e discussões de outras áreas do conhecimento e ciências? Todas essas foram questões que pautaram debates que contribuíram sobremaneira para que a Educação Física caminhasse alguns passos à frente na busca de sua identidade acadêmica enquanto campo/área do conhecimento.

Em meio a esta crise, Manuel Sérgio é figura importante para a Educação Física brasileira na medida em que também trabalhou no sentido de elaborar uma crítica para a Educação Física criando a sua teoria. A Educação Física deveria substituir o conceito anátomo-fisiológico por um conceito bio-psico-sócio-filosófico, no qual o prazer, o desenvolvimento integral e o aspecto educacional ficassem sempre ressaltados. As especificidades e reducionismos sob as quais a Educação Física se pautava eram vistas por Manuel Sérgio como insuficientes - ou no mínimo reducionistas - para se explicar a complexidade de uma prática que articula problemas de um humano/corpo físico, psicológico, sagrado, cultural, econômico, político. Por isso ele busca pensar a Educação Física a partir de um novo paradigma: o da "Ciência da Motricidade Humana".

\begin{abstract}
A Ciência da Motricidade Humana não nega o físico. Chama, no entanto, a atenção para o fato de a motricidade exprimir a complexidade humana e não apenas o físico. E a complexidade humana é, de modo mais evidente, corpomente-natureza-desejo-sociedade. Pode-se resumir da seguinte forma a mensagem da Ciência da Motricidade Humana: provoca um "corte epistemológico" no seio da Educação Física, fazendo nascer uma nova ciência humana (TOJAL, 2005 p. 294).
\end{abstract}

A principal crítica de Manuel Sérgio no que tange a Educação Física estava essencialmente na crítica do modelo de ciência cartesiana e no positivismo, ciência essa que tentava explicar os acontecimentos através dos cálculos matemáticos e a divisão entre corpo e alma/mente. A Ciência da Motricidade Humana é um corte epistemológico e um paradigma emergente na medida em que tem como principal objetivo uma nova visão e compreensão do que seja a ciência e o corpo e sua relação com um todo. De acordo com Sérgio (1995, p. 40):

Por dentro de uma visão holística do homem e do universo tudo está em tudo e por tudo o homem realiza e se realiza; pela práxis transformadora, o homem abre acesso à transcendência e toma consciência de que não é objeto, mas sujeito fazedor da história e doador de sentido.

A Ciência da Motricidade Humana revela total comunhão entre o homem e o mundo e entre o homem e seu corpo. O homem é formado pela alma e o corpo, assim tem total consciência do seu papel no mundo, deixando de ser apenas um ser-diante-domundo e passando a ser elemento do próprio mundo. O homem é um ser práxico, diferente dos animais que nascem providos de recursos biológicos e instintos que garantem sua existência. O homem é o ser maleável, que se modifica conforme a situação e através da cultura ele cria objetos, máquinas, seus produtos para sua sobrevivência. O homem modifica a si mesmo e o ambiente para permanecer vivo. De acordo com Sérgio (1995, p. 27): 
E, porque o Homem é um ser carenciado e consciente dessa carência, não só a insatisfação nele ressoa tensa e intensa, no mais fundo de si mesmo, como a motricidade é anterior à ideia de carência e, por vezes, independe dela. $\mathrm{O}$ Homem move-se, para superar e superar-se, como respira...: naturalmente! Todavia, a consciência dessa carência empurra o Homem a um fieri contínuo, a um incessante fazer e fazer-se.

A Motricidade Humana idealizada por Manuel Sérgio tem também como foco a formação de profissionais mais capacitados para atuar no campo da Educação Física, pois, segundo ele, a Educação Física estava apenas interessada no desenvolvimento das faculdades físicas do indivíduo pautadas nas ciências físico-biológicas. Em contrapartida a Motricidade Humana se refere a todo um corpo que supera os limites da anatomia; um corpo memória, um corpo estrutura, um corpo conduta, um corpo transcendência, um corpo em devir, um corpo intencional. Desta forma Manuel Sérgio sugere a implantação de Faculdades de Motricidade Humana para formar licenciados (mestre ou doutores), profissionais capacitados para trabalhar com a Educação Física. Importante dizer que por ter esta visão de corpo/humano para além do físico, Manuel Sérgio é totalmente contra o termo "Educação Física", sendo que, para ele, este campo de conhecimento/ciência deveria se denominar "Ciência da Motricidade Humana".

A Ciência da Motricidade Humana representou uma mudança de modelo no ambiente da educação escolarizada. Para Manuel Sérgio não existe Educação Física, mas sim educação motora e essa sendo um ramo da motricidade humana. De acordo com Sérgio (1999, p. 113):

A educação física ou educação motora (o desporto, a dança, a ergonomia e a reabilitação) forma o conteúdo pedagógico pode assumir (criticamente) a capacidade de saber se teoria, um programa de investigação, que pesquise as condições de possibilidade dos conhecimentos que permitem novas racionalidades e por fim, de refletir em termos gerais fundamento, o homem, a sociedade, a natureza e a história.

Manuel Sérgio pautou a Ciência da Motricidade Humana na importância do homem na sua relação com o mundo. Para tal sua visão de ciência, de mundo e de homem foi influenciada pela filosofia de Bachelard, Althusser, Popper, Kuhn, Lakatos, Feyerabend, Foucault, Morin, Hegel, Nietzsche, Merleau-Ponty e Marx. Em suma, a Ciência da Motricidade Humana demonstra um modo de ver e pensar o mundo e o homem, bem como a interação e conexão complexa entre essas coisas. Desta forma a $\mathrm{CMH}$ quebrou com os paradigmas da ciência cartesiana e positivista, apresentou outra maneira de fazer e conceituar ciência e revelou a importância do homem enquanto corpo intencional que persegue a transcendência.

\section{Metodologia}

A amostra do estudo compreendeu textos completos que abordam a temática da Motricidade Humana de doze periódicos da Educação Física brasileira. As revistas analisadas foram avaliadas pelo Qualis periódicos da $\mathrm{CAPES}^{4}$ na área Educação Física com o conceito A (A1 e A2) e B (B1, B2, B3 e B4). Compreendendo este critério, o levantamento do corpus (conjunto de textos analisados na pesquisa) foi realizado a partir de pesquisa nos seguintes periódicos: Movimento/UFRGS; Motriz/SP; Revista

\footnotetext{
${ }^{4}$ Este é o parâmetro "Qualis 2014", obtido no do dia 19 de setembro de 2016 na plataforma Sucupira.
} 
Brasileira de Ciências do Esporte/RBCE; Revista Brasileira de Educação Física e Esporte/USP; Revista da Educação Física UEM; Licere/UFMG; Motrivivência/UFSC; Pensar a Prática/UEG; Revista Brasileira de Atividade Física e Saúde; Revista Brasileira de Ciência e Movimento/UCB; Revista Mackenzie de Educação Física e Esporte/SP; Kinesis/UFSM.

O recorte temporal adotado abrange os anos de 2000 até 2015 , sendo pesquisados todos os textos publicados nos periódicos selecionados que se encontram no escopo desse recorte temporal. O levantamento dos dados empíricos foi realizado no banco de dados dos periódicos utilizando a ferramenta de busca disponível on-line, selecionando os filtros "título" e "resumo" para aplicar o termo de busca "motricidade humana". Em seguida, para fins de contabilização e enumeração dos artigos, tais dados foram transferidos para uma planilha confeccionada no software Excel da Microsoft e organizados, primeiramente, em forma de lista segundo as seguintes informações técnicas: a) título; b) resumo; c) volume; d) edição.

A partir dessa lista inicial de artigos, foram efetivadas algumas exclusões conforme os seguintes critérios: a) textos de anais de eventos; b) textos apresentados sob a forma de resumo; c) resenhas de livros; d) textos que extrapolavam para mais ou para menos o recorte temporal de 2000-2015; e) textos que apresentam o termo Motricidade Humana sob uma perspectiva epistemológica diferente da Ciência da Motricidade Humana proposta por Manuel Sérgio. A partir dos dados apresentados nessa tabela foram criadas categorias analíticas que fundamentaram percepções sobre as representações da Motricidade Humana em contextos de pesquisa no Brasil, contemplando o objetivo central desse trabalho.

Entende-se que a produção em periódicos é, em grande medida, representativa da produção mais geral em um determinado campo científico, pois mesmo o material publicado em livros, anais e objetos de dissertações e teses tendem, ao menos em parte, a serem veiculados em periódicos. Destaca-se também a importância da avaliação por pares para a legitimação dos trabalhos publicados em periódicos.

\section{APRESENTAÇÃO E ANÁLISE DOS DADOS}

A captura inicial dos textos utilizando as ferramentas de busca on-line das revistas selecionando os filtros limitados a "títulos" e "resumos" resultou num quantitativo de 24 textos. Com a amostra em mãos foram aplicados os critérios de corte descritos na metodologia, restringindo a amostra a 17 artigos. Dos 17 textos de nosso quantitativo, somente 10 deles tratavam de "Motricidade Humana" sob a perspectiva epistemológica oriunda da teoria de Manuel Sérgio. Os outros 7 textos eram textos com perspectivas diferentes que compreendem a motricidade humana como sendo um termo que faz alusão ao movimento humano, movimento este proveniente de vertentes epistemológicas pautadas nas teorias de crescimento e desenvolvimento humano que tem como bases as ciências biológicas e psicológicas. Abaixo, a tabela 1 apresenta os textos eleitos para análise, com o periódico em que foi feita a publicação e o ano de publicação.

TABELA 1: Título do artigo, periódico e ano de publicação.

\begin{tabular}{l|c|c}
\cline { 2 - 3 } & TÍTULO & PERIÓDICO/ANO \\
\hline \multirow{2}{*}{ Texto 1 } & Reconstruindo o lazer a partir de um periódico científico & MOTRIZ \\
& & 2005 \\
\hline & Vivências em arte circense: motivos de aderência e & MOTRIZ \\
Texto 2 & expectativas & 2007 \\
\hline Texto 3 & Ciência e o conceito de corpo e saúde na Educação Física & MOTRIZ \\
\hline
\end{tabular}

Motricidades: Rev. SPQMH, v. 2, n. 1, p. 32-44, jan.-abr. 2018 | ISSN 2594-6463 |

DOI: http://dx.doi.org/10.29181/2594-6463.2018.v2.n1.p32-44 


\begin{tabular}{|c|c|c|}
\hline & & 2009 \\
\hline Texto 4 & $\begin{array}{l}\text { Ecomotricidade: sinergia entre educação ambiental, } \\
\text { Motricidade Humana e pedagogia dialógica }\end{array}$ & $\begin{array}{l}\text { MOTRIZ } \\
2009\end{array}$ \\
\hline Texto 5 & $\begin{array}{c}\text { Dialogando sobre a capoeira: possibilidades de intervenção } \\
\text { a partir da motricidade humana }\end{array}$ & $\begin{array}{l}\text { MOTRIZ } \\
2009\end{array}$ \\
\hline Texto 6 & $\begin{array}{c}\text { O ensino da Motricidade Humana nos currículos dos } \\
\text { cursos de Educação Física }\end{array}$ & $\begin{array}{l}\text { Ciência e Movimento } \\
2010\end{array}$ \\
\hline Texto 7 & $\begin{array}{l}\text { Valores como conteúdo da educação Física escolar: } \\
\text { perspectiva a partir da Motricidade Humana }\end{array}$ & $\begin{array}{l}\text { Ciência e Movimento } \\
2011\end{array}$ \\
\hline Texto 8 & $\begin{array}{c}\text { Convergência e integração: uma proposta para a educação } \\
\text { Física de } 5^{\mathrm{a}} \text { a } 8^{\mathrm{a}} \text { série do Ensino Fundamental }\end{array}$ & $\begin{array}{l}\text { RBEFE } \\
2008\end{array}$ \\
\hline Texto 9 & $\begin{array}{l}\text { Corporeidade: por uma abordagem humanizadora do corpo } \\
\text { em busca da existencialidade }\end{array}$ & $\begin{array}{l}\text { Mackenzie } \\
2010\end{array}$ \\
\hline Texto 10 & Motricidade humana e saúde & $\begin{array}{l}\text { Revista da UEM } \\
2001\end{array}$ \\
\hline
\end{tabular}

Dos 12 periódicos pesquisados, 5 veicularam textos sobre a temática da Motricidade Humana e os outros 7 periódicos não publicaram textos relativos ao tema. Os 10 textos ficaram assim distribuídos entre os 5 periódicos: Motriz - Revista de Educação Física da UNESP de Rio Claro (5 textos), Revista Brasileira de Ciência e Movimento da Universidade Católica de Brasília (2 textos), Revista Brasileira de Educação Física e Esportes da USP - RBEFE (1 texto), Revista Mackenzie de Educação Física e Esporte (1 texto) e Revista de Educação Física da Universidade Estadual de Maringá - UEM (1 texto). Dos 10 textos publicados, 7 foram veiculados em revistas do estado de São Paulo, 2 em Brasília - Centro-Oeste brasileiro, e 1 texto publicado num periódico da região Sul, no estado do Paraná.

Os 10 textos foram assinados por 15 autores (8 mulheres e 7 homens), sendo que Jossett Campagna de Gáspari e Luiz Gonçalves Junior assinaram dois textos cada. No que tange à nacionalidade, 1 autor é de Portugal e os outros 14 são brasileiros. A titulação dos autores é de 2 pós doutores, 8 doutores, 4 mestres e 1 graduado. Sobre a formação inicial dos autores temos: 1 filosofia (o próprio Manuel Sérgio que assinou um dos textos); 1 pedagogia; 1 psicologia e 1 autora tem 2 formações iniciais (pedagogia e serviço social); os 11 demais autores são formados em Educação Física. Importante mencionar que todos os 11 autores com formação inicial em Educação Física fizeram seus cursos em instituições paulistas: UNESP/UFSCar/PUC/Metodista de Piracicaba. Dos outros três autores brasileiros, 1 autora fez seu mestrado e doutorado em "Ciência da Motricidade Humana" na UNESP; as outras duas autoras são formadas em pedagogia e psicologia e fizeram seus estágios pós-doutorais na Faculdade do Porto em Portugal.

Se observarmos que 7 dos 10 textos foram veiculados em revistas paulistas de Educação Física e que 11 dos 15 autores se formaram em Educação Física em instituições paulistas, fica evidente que a teoria da Motricidade Humana se disseminou com maior ênfase no estado de São Paulo. Sobre a nacionalidade dos autores, seria interessante a ampliação futura da pesquisa para outros periódicos da América Latina, sendo os resultados comparativos significativos tanto para a representação geral da produção da Motricidade Humana na macrorregião (América Latina), como na comparação de como o tema é representado nos diferentes países que compõe essa macrorregião. Essa possibilidade é enfatizada pelo conhecimento dos autores desse artigo sobre a produção de textos que referenciam a Motricidade Humana em países como Argentina, Chile, Colômbia e Equador. Da mesma forma, a ampliação futura da pesquisa considerando uma gama maior de periódicos brasileiros associados a outras áreas do conhecimento, por exemplo, educação, ciências ambientais ou outras 
disciplinas do campo da saúde, poderá indicar se o tema se configura como uma representação específica do campo da Educação Física, ou se há representatividade do tema em outros campos do conhecimento e, nesse caso, como o tema seria representado nas diferentes áreas.

O estudo bibliométrico depende de um exercício prévio de nomeação segundo as qualidades dos objetos a serem quantificados, pois se enumera tanto os objetos na formação de conjuntos, quanto qualidades ou características de um mesmo objeto - "O nome é um artifício imprescindível para o reconhecimento do ser: para que algo seja estudado é preciso nomeá-lo" (PEREIRA, 2004, p. 30). Entre tomar contato empírico com o objeto e pensar o objeto existe o problema crucial da qualificação ou caracterização do objeto a partir de algum fundamento classificatório ou categorial.

Mencionamos isso na medida em que quando partimos para a análise das temáticas apresentadas nas publicações sobre Motricidade Humana pensávamos em indutivamente enumerar características que pudessem agrupar os textos por categorias temáticas. Porém, a variação de conteúdos dentro das temáticas tratadas não nos permitiu criar categorias com limites claros, que não deixassem escapar a caracterização de cada estudo para a composição com os demais. Desta forma, optamos por apresentar as temáticas encontradas estabelecendo tensivas de aproximação, mas que não necessariamente são temáticas fixas e que não se relacionam com as demais. Sendo assim, passamos agora a descrever as temáticas encontradas nos textos analisados.

Dois textos discorreram sobre aspectos epistemológicos a partir do mapeamento da produção do conhecimento e do diálogo científico que a Educação Física tem com outros campos do saber. Ambos os textos não trataram diretamente da teoria da Motricidade Humana, mas investigaram a inserção dela nos estudos de lazer e na proposição de uma abordagem da Educação Física escolar a partir de uma pedagogia inter e transdisciplinar.

O trabalho de Gáspari (2005) teve como objetivo identificar, de 1995 a 2000, como o lazer foi veiculado na revista Motriz; como parte do resultado a autora menciona que no período investigado constata-se a predominância das publicações científicas na Área de Concentração da Pedagogia da Motricidade Humana, tendo, como denotam, o aspecto pedagógico como elemento condutor. O texto de Sanches Neto e Betti (2008) apresenta e analisa uma proposta para fundamentar a intervenção de professores de Educação Física da $5^{\mathrm{a}}$ à $8^{\mathrm{a}}$ série do Ensino Fundamental. Como a Educação Física mantém relações com diversos campos científicos, os autores trataram de analisar as principais perspectivas nessa área, identificando cinco discursos de pretensão científica os quais defendem diferentes compreensões para associar a Educação Física às Ciências: Cinesiologia, Ciência da Motricidade Humana, Ciências do Esporte, Cultura Corporal de Movimento e Aptidão Física relacionada à Saúde. A partir dessas perspectivas, os autores identificaram diferentes propostas que foram elaboradas para contemplar a intervenção profissional em Educação Física e consideraram que há uma convergência entre as diversas tendências, tanto em relação às áreas de estudos científicos como às abordagens para a Educação Física Escolar. Os autores também mencionam que os Parâmetros Curriculares Nacionais possibilitaram alguma aproximação entre as tendências, no entanto, seus princípios curriculares, particularmente os conteúdos, limitaram-se quanto à abrangência, pois as relações estabelecidas entre as áreas de estudos e a proposta de intervenção foram precárias (SANCHES NETO; BETTI, 2008).

Percebemos nesses dois estudos uma perspectiva epistemológica no sentido de que ambos refletem sobre as diferenças entre tradição e epistemologia nas pesquisas e teorias da área, tendo como pano de fundo as interações e rupturas entre senso comum e 
conhecimento científico. Os dois estudos se aproximam também, pois tratam da problemática acerca do estatuto científico em termos de um modelo teóricometodológico do campo concernente à sua dependência e independência em relação a outras ciências.

Em termos epistemológicos ainda encontramos 3 estudos que tratam do conceito de saúde e do conceito de corpo. Estes estudos se pautam na desconstrução de dualismos, que é um dos principais fundamentos da construção teórico-metodológica das ciências modernas em geral e, logicamente, da Educação Física.

O texto de Sérgio (2001) propõe o estudo da saúde sob o prisma da Motricidade Humana, já que esta estuda as condutas motoras em um ser humano que persegue a transcendência. Para propor uma concepção de saúde no âmbito de sua teoria, Manuel Sérgio parte dos paradigmas da transdisciplinaridade e da complexidade. O estudo de Novaes (2009) discute dois conceitos caros à Educação Física: o corpo e a saúde. A partir da teoria da Motricidade Humana o autor tece críticas ao modelo hegemônico no trato da saúde pautado na racionalidade médica e na biologização do corpo. $\mathrm{O}$ autor acredita que a ruptura paradigmática de homem/mundo pautada pela Ciência da Motricidade Humana é central para repensarmos o corpo e a saúde no campo da Educação Física. Inforsato e Fiorante (2010) apresentam em forma de ensaio uma visão de corporeidade livre das concepções mecanicistas e dualistas oriundas do racionalismo cartesiano. Para tal, fazem uso de teorias que concebem o corpo a partir da complexidade, fazendo alusão também à Educação Motora enquanto ramo pedagógico da Ciência da Motricidade Humana.

A discussão epistemológica de corpo sempre foi central nos textos elaborados por Manuel Sérgio na estruturação da Ciência da Motricidade Humana. Arriscamos dizer que talvez a obra central nesse contexto tenha sido o livro "Alguns olhares sobre o corpo" lançado em 2003 pela editora do Instituto Piaget (SÉRGIO, 2003). Neste livro Manuel Sérgio faz uma contextualização histórico-filosófica do corpo estabelecendo tensões com autores da filosofia que se debruçaram sobre a temática do corpo. Sérgio faz fortes críticas ao racionalismo cartesiano através das vozes de Merleau-Ponty e Nietzsche, propondo um corpo para a Ciência da Motricidade Humana. Para Manuel Sérgio o ser humano é um corpo em movimento intencional que persegue a transcendência, busca a superação em nível integral, não somente em termos físicobiológico. Nesta mesma linha epistemológica Sérgio vai pautar os preceitos que sustentam o conceito de saúde na esfera de sua teoria: “[...] a saúde como capacidade de superação" (SÉRGIO, 1999, p. 38).

A importância de estudar o corpo sob o viés da Motricidade Humana já vem destacada como resultado do estudo de Bugarim e Nascimento (2010). As autoras apresentam um estudo que teve como objetivo investigar a compreensão dos docentes sobre a inserção da Motricidade Humana nos currículos dos cursos de licenciatura plena em Educação Física. A amostra da pesquisa foi composta por 40 professores licenciados em Educação Física de três municípios do estado do Pará (esses professores eram egressos do curso de Educação Física do município de Tucuruí-PA). Como parte dos resultados, $40 \%$ dos entrevistados entendem que a presença da Motricidade Humana no currículo permite o estudo do corpo com mais consciência (BUGARIM; NASCIMENTO, 2010).

No estudo de Bugarim e Nascimento (2010) conseguimos visualizar a temática ligada ao âmbito pedagógico que trata da formação inicial e do currículo. O currículo contempla aquilo que os estudantes precisam ou devem aprender através do que é formalmente ensinado. $\mathrm{Na}$ formação inicial em Educação Física (licenciatura e bacharelado) existem currículos que tratam de bases epistemológicas e filosóficas. 
Acreditamos e defendemos que a teoria da Motricidade Humana deve ser apresentada e estudada como conteúdo dessas disciplinas.

$\mathrm{Na}$ análise dos dados empíricos de nosso corpus encontramos outro artigo que trata de questões críticas e propositivas no que tange as questões de fundamentos e propostas pedagógicas destinadas a compor o conjunto de paradigmas da docência em Educação Física. O trabalho de Freire, Silva e Miranda (2011), intitulado: "Valores como conteúdo da Educação Física escolar: perspectivas a partir da Motricidade Humana", discute os valores que podem constituir o currículo de uma proposta de Educação Física escolar que se fundamente nos pressupostos da Ciência da Motricidade Humana. Pautadas em trabalhos produzidos por estudiosos da Motricidade Humana as autoras propõem conceitos da teoria, tais como: liberdade; consciência; transcendência; intencionalidade; criatividade e autonomia para servirem como base de valores no trato do humano na sua relação com o corpo e o movimento no contexto da Educação Física escolar.

Ambos os estudos descritos são trabalhos responsáveis por refletir sobre os conhecimentos filosóficos, científicos e ideológicos, bem como aqueles chamados de tácitos - quando adquiridos durante a empiria da docência -, necessários para a formação docente na universidade e para seu trabalho pedagógico no campo de trabalho escolar ou não. Em sua especificidade, trata-se de estudos que apresentam sugestões e possibilidades teóricas, conceituais e políticas para com os tratos metodológicos no tocante ao ensino das práticas corporais, tanto relacionadas à aplicação em escolas quanto à preparação de seus profissionais na formação inicial nas universidades (TERRA NOVA et al., 2015).

Outro agrupamento temático possível em nossa análise foi o de práticas corporais discutidas sob o umbral da Motricidade Humana. Gonçalves Junior (2009) apresenta um estudo que tem como principal objetivo discorrer sobre os desdobramentos da capoeira vislumbrando possibilidades de intervenção tendo como suporte a Ciência da Motricidade Humana de Manuel Sérgio e a Pedagogia Dialógica de Paulo Freire, as quais, entre outras influências em suas respectivas constituições, têm a fenomenologia existencial de Merleau-Ponty. Com objetivos próximos, Rodrigues e Gonçalves Junior (2009) estabelecem tensões/sinergias entre a Educação Ambiental Crítica, a Motricidade Humana e a Pedagogia Dialógica de Paulo Freire a fim de pensar as práticas corporais na natureza. O texto tem um comprometimento epistemológico com a teoria da Motricidade Humana na medida em que os autores contribuem com o aprofundamento teórico da "ecomotricidade", definida como práticas corporais desenvolvidas com intencionalidade relacionada a processos educativos de reconhecimento das relações ser humano-meio ambiente. Gáspary e Schwartz (2007), através de um curso de extensão denominado "vivências em artes circenses" - proposto pelo Laboratório de Estudos do Lazer do Departamento de Educação Física da UNESP/Rio Claro, buscam incidir sobre os motivos de aderência e expectativa que levaram jovens universitários a fazer o curso de circo. Ao final as autoras mencionam que, considerando as potencialidades lúdica, prazerosa e agregadora das práticas de circo, estas precisam ser aperfeiçoadas sob a luz da teoria da Motricidade Humana com finalidade de incremento nos processos de formação profissional do campo.

O objeto de estudo da Motricidade Humana é o desenvolvimento humano a partir da motricidade, pelo estudo do corpo e suas manifestações na interação dos processos biológicos com valores socioculturais e a natureza. Para tal, Manuel Sérgio propôs um domínio organizado desse saber, a partir do que ele denominou subsistemas do sistema da Motricidade Humana: o desporto, a dança, a ergonomia, a Educação Especial e reabilitação (SERGIO, 1999). Porém, estes subsistemas não estão fechados. 


\begin{abstract}
A ciência da Motricidade Humana (que se sabe em crise, porque está viva) quer trazer a esta área do conhecimento uma incessante complexidade, uma racionalidade dialogante e aberta. Integram-na o desporto, a dança, a ergonomia, a educação especial e reabilitação e ainda os vários tipos de motricidade infantil e o lazer lúdico-desportivo (SÉRGIO, 1999, p. 27).
\end{abstract}

Fica claro assim que as práticas de circo, as manifestações corporais de lutas desenvolvidas sob a perspectiva da capoeira - e a ecomotricidade são práticas incorporadas pela Ciência da Motricidade Humana, pois são movimentos intencionais na busca da transcendência, manifestações culturais apresentadas para além de uma rasa fundamentação tecnicista que reduz o corpo às suas dimensões físico-biológicas.

\title{
CONSIDERAÇÕES FINAIS
}

Retomando o objetivo do presente artigo, que foi o de analisar a produção do conhecimento da temática "Motricidade Humana" em periódicos da Educação Física brasileira classificados como A1, A2, B1, B2, B3 e B4 pelo WebQualis da Capes, no período de 2000-2015, apresentamos como principais resultados a inferência de que a teoria da Motricidade Humana está fortemente vinculada, principalmente, aos cursos de formação em Educação Física do estado de São Paulo; em relação às publicações sobre a temática, a veiculação dos textos também se dá, predominantemente, em periódicos Paulistas.

No que tange as temáticas trabalhadas nos dez textos percebemos uma rica diversidade: textos epistemológicos de análise da produção de conhecimento; textos epistemológicos que tratam da concepção de corpo e de saúde; estudos que apresentam possibilidades com os tratos metodológicos no ensino das práticas corporais relacionadas à aplicação em escolas e na formação inicial nas universidades; textos que versam sobre as práticas corporais - capoeira, ecomotricidade e circo - sob o viés da Ciência da Motricidade Humana.

O total de 10 textos encontrados sinaliza que a "Motricidade Humana" ainda é marginal no que tange a pesquisas e publicações no âmbito do campo da Educação Física no Brasil. Os temas trabalhados nos textos ainda não dão conta de problemáticas inerentes às ricas contribuições que a Ciência da Motricidade Humana pode oferecer ao campo da Educação Física. Nesse sentido, reforça-se a orientação para futuras pesquisas que ampliem o olhar sobre a produção acadêmica na temática, seja em outros periódicos brasileiros, abrangendo outras áreas do conhecimento, ou em periódicos de outros países da América Latina.

As conclusões que chegamos foram feitas a partir de nossa amostra e sabemos que o que aqui trazemos está recortado dentro de um tempo e de um espaço específico, o que nos permite reconhecer a previsibilidade dos conhecimentos aqui estruturados. Sabemos que a nossa amostra empírica, reduzida a publicações em revistas da Educação Física avaliadas como A1, A2, B1, B2, B3 e B4 pela WebQualis Capes, pode não representar a totalidade de um campo que não reduz suas pesquisas a estes periódicos. Porém, expressamos a significativa representatividade da amostra diante dos parâmetros nacionais de avaliação da produção científica, na esperança de que essa amostra inicial contribua para outras pesquisas que abordem a produção do conhecimento relacionada ao tema da Ciência da Motricidade Humana.

\section{REFERÊNCIAS}

BRACHT, V. Educação física \& ciência: cenas de um casamento (in)feliz. IJuí: Unijuí, 1999. 
Cae Rodrigues; Fabio Zoboli; Luis Henrique Calazans

BRACHT, V.; FARIA, B. A.; ALMEIDA, F. Q.; GHIDETTI, F. F.; GOMES, I. M.; ROCHA, M. C.; MACHADO, T. S.; ALMEIDA, U. R. MORAES, C. E. A. A educação física escolar como tema da produção do conhecimento nos periódicos da área no Brasil (1980-2010): parte 1. Movimento, v. 17, n. 2, p. 11-34, 2011.

BRACHT, V.; FARIA, B. A.; MORAES, C. E. A.; FERNANDES, E. S.; ALMEIDA, F. Q.; GHIDETTI, F. F.; GOMES, I. M.; ROCHA, M. C.; MACHADO, T. S.; ALMEIDA, U. R.; PENHA, V. M. A educação física escolar como tema da produção do conhecimento nos periódicos da área no Brasil (19802010): parte 2. Movimento, v. 18, n. 2, p. 11-37, 2012.

BUGARIM, M. C. P; NASCIMENTO, M. A. L. O ensino da motricidade humana nos currículos dos cursos de educação física. Revista brasileira de Ciência e Movimento, v.18, n. 2, 19-25, 2010.

CAPARROZ, F. E.; BRACHT, V. O tempo e o lugar de uma didática da educação física. Revista Brasileira de Ciências do Esporte, v. 28, n. 2, p. 21-37, 2007.

FREIRE, E. S.; SILVA, S. A. P.; MIRANDA, M. L. J. Valores como conteúdo da educação física escolar: perspectiva a partir da motricidade humana. Revista brasileira de Ciência e Movimento, v. 19, n. 4, p. 89-96, 2011.

GAMBOA, S. S. Teoria e prática: uma relação dinâmica e contraditória. Motrivivência, n. 8, p. 31-45, 1995.

GÁSPARI, J. C. Reconstruindo o lazer a partir de um periódico científico. Motriz, v. 11, n. 2, p. 131-140, 2005.

GÁSPARI, J. C.; SCHWARTZ, G. M. Vivências em arte circense: motivos de aderência e expectativas. Motriz, v. 13, n. 3, p. 158-164, 2007.

GONÇALVES JUNIOR, L. Dialogando sobre a capoeira: possibilidades de intervenção a partir da motricidade humana. Motriz, v. 15, n. 3, p. 700-707, 2009.

INFORSATO, C. F.; FIORANTE, F. B. Corporeidade: por uma abordagem humanizadora do corpo em busca da existencialidade. Revista Mackenzie de Educação Física e Esporte, v. 9, n. 2, p. 135-144, 2010.

KUNZ, E. Educação Física: ensino e mudanças. Ijuí: Unijuí, 1991.

MEDINA, J. P. S. A Educação Física cuida do corpo e..."mente": bases para a renovação e transformação da educação física. Campinas: Papirus, 1983.

NOVAES, C. R. B. Ciência e o conceito de corpo e saúde na Educação Física. Motriz, v. 15, n. 2, p. 383$395,2009$.

PEREIRA, J. C. R. Análise de dados qualitativos: estratégias metodológicas para as Ciências da Saúde, Humanas e Sociais. 3. ed. São Paulo: Editora da Universidade de São Paulo, 2004.

RODRIGUES, C.; GONÇALVES JUNIOR, L. Ecomotricidade: sinergia entre educação ambiental, motricidade humana e pedagogia dialógica. Motriz, v. 15, n. 4, p. 987-995, 2009.

ROMANOWSKI, J. P.; ENS, R. T. As pesquisas denominadas do tipo "estado da arte" em educação. Diálogo Educacional, v. 6, n. 19, p. 37-50, 2006.

SANCHES NETO, L.; BETTI, M. Convergência e integração: uma proposta para a educação física de $5^{\text {a }}$ a $8^{\text {a }}$ série do ensino fundamental. Revista brasileira de Educação Física e Esporte, v. 22, n. 1, p. 5-23, 2008.

SÉRGIO, M. Alguns olhares sobre o corpo. Lisboa: Instituto Piaget, 2003. 
SÉRGIO, M. Motricidade Humana e saúde. Revista da Educação Física/UEM, v. 12, n. 2, p. 129-138, 2001.

SÉRGIO, M. Um corte epistemológico: da educação física à motricidade humana. Lisboa: Instituto Piaget, 1999.

SÉRGIO, M. Motricidade humana: um paradigma emergente. Blumenau: Editora da FURB, 1995.

SOARES, C. L.; TAFFAREL, C. N. Z.; VARJAL, E.; CASTELLANI FILHO, L.; ESCOBAR, M. O., BRACHT, V. Metodologia do ensino da educação física. São Paulo: Cortez, 1992.

TERRA NOVA, J. V. S.; GOIS, C.; ZOBOLI, F.; BOMFIM, E. S. M.; OLIVEIRA, S. S.; SILVA, R. I. Tema corpo nas publicações da revista Motriz (1995-2012). Educação Física em Revista, v. 9, n. 1, p. 74-95, 2015.

TOJAL, J. B. A. G. Motricidade Humana. In: FENSTERSEIFER, P. E.; GONZALEZ, F. J. Dicionário crítico de Educação Física. Ijuí: Editora Unijuí, 2005. p. 292-295.

Recebido em: 22 dez. 2017.

Aprovado em: 07 abr. 2018. 